University of St. Thomas, Minnesota

UST Research Online

2009

\title{
An Investigation of Nonprofessional Investors, Qualitative Materiality Judgments Incorporating SEC Listed vs. Non-Listed Events
}

\author{
Terence Pitre \\ University of St. Thomas, Minnesota, pitr4066@stthomas.edu \\ Ronald Daigle \\ Robert Pinsker
}

Follow this and additional works at: https://ir.stthomas.edu/ocbacctpub

Part of the Accounting Commons

This Article is brought to you for free and open access by the Accounting at UST Research Online. It has been accepted for inclusion in Accounting Faculty Publications by an authorized administrator of UST Research Online. For more information, please contact asle4660@stthomas.edu. 


\title{
An Investigation of Nonprofessional Investors' Qualitative Materiality Judgments Incorporating SEC Listed vs. Non- listed Events
}

\author{
Robert Pinsker \\ Associate Professor of Accounting \\ Department of Accounting \\ Old Dominion University \\ 2140 Constant Hall \\ Norfolk, VA 23529 \\ Phone: (757) 683-6553 \\ Email: rpinsker@odu.edu \\ Terence J. Pitre \\ Assistant Professor \\ Department of Accounting \\ Opus College of Business \\ University of St. Thomas \\ Minneapolis MN 55403 \\ Phone: (651)-962-4246 \\ Fax: (651)962-4710 \\ Email: tjpitre@stthomas.edu \\ Ronald Daigle \\ Associate Professor of Accounting \\ Department of Accounting \\ College of Business Administration \\ Box 2056 \\ Sam Houston State University \\ Huntsville, TX 77341-2056 \\ Email: daigle@shsu.edu
}

Professor Pinsker appreciatively acknowledges the financial funding from a grant at Old Dominion University. Additionally, the authors gratefully acknowledge the helpful comments and suggestions from the Editor, two anonymous referees, Mike Stein, Scott Vandervelde, Jim Lampe, Tim Louwers, Bryan Church, Shawn Davis, Paul Polinski, and Christian Mastilak. 


\begin{abstract}
When the SEC began listing specific potentially material events in its Regulation FD (2000), it deviated from its long-time "policy" of not providing materiality guidance to auditors and managers. What is currently unclear in the materiality literature is which factor(s) information-based characteristics or user-based characteristics - has an effect on nonprofessional investor qualitative materiality judgments. Using a series of experimental markets, we examine and find no evidence that an information-based characteristic (distinguishing between listed and non-listed events) has an effect on nonprofessional investors’ materiality judgments. Our evidence regarding user-based characteristics is mixed. We do not find evidence of the direction of disclosed events impacting investors' judgments, but we do find evidence of an anchoring effect. Our findings indicate that the content of the information disclosed to nonprofessional investors is not as important as the timing of the disclosure. Our investigation is unique in that we consider the (qualitative) nature of the event, rather than simply its (quantitative) magnitude.
\end{abstract}

Keywords: belief revision, materiality, information processing, disclosure.

Data Availability: Data are available from the first author upon request. 


\section{Introduction}

"In the past, if you asked people about materiality, it was focused more on a quantitative analysis. In light of SOX, the qualitative is now as important if not more important," Thomas Connors, audit partner of Deloitte \& Touche, commenting how Sarbanes-Oxley has played a role in heightening the debate about materiality (Whitehouse, 2007, 3-4).

The nature of an economic event is an important determinant of materiality (Patillo, 1976; Sengupta, 2004; Messier et al., 2005) and can affect investor judgments (Tuttle et al. 2002). The staff at the Securities and Exchange Commission (SEC) is considering whether to update its views (i.e., Staff Accounting Bulletin (SAB) 99, (1999)) on the role of qualitative factors involved with materiality judgments (Whitehouse, 2007; Taub, 2007). U.S. policy makers have expressed concern that firms misuse materiality rules in order to meet earnings thresholds by not correcting quantitatively small items from the financial statements that have the potential to be qualitatively material (Levitt, 1998). ${ }^{1}$ The issue is also attracting international attention. The International Auditing and Assurance Board (IAASB) has recently initiated a comprehensive review and revision of the international auditing standard on materiality in response to increased recognition of the need for greater consideration of qualitative materiality among auditors (International Federation of Accountants, 2006).

These deliberations have implications for both practice and academia. With respect to practice, for the first time in their history, the SEC has provided specific events auditors and other decision makers should "pay close attention to" (i.e., are more likely to be material than other events, situation specific), when making qualitative materiality determinations. ${ }^{2}$ In their Regulation Fair Disclosure (2000; henceforth, FD), the SEC responds to commenters' suggestions for more interpretive materiality guidance by listing seven events that can potentially be material (e.g., earnings information and bankruptcies). The SEC indicates that the seven events are not automatically "material," per se, but likely could be and, therefore, should be 
reviewed carefully. Section 409 of the Sarbanes-Oxley Act of 2002 (SOX) charges the SEC to adjust disclosure requirements. The SEC has responded with eight additional events (e.g., entry into and termination of a material definitive agreement) along with two expansions of existing events that likely could be material.

Schipper's (2007) comments regarding materiality of disclosures serves as a lead for academic-based implications. Schipper (pp. 314-315) considers if user-based characteristics, rather than information-based characteristics, drive materiality determinations. If so, auditors "may reach different materiality judgments... we simply do not know much about auditor assumptions about financial statement users, and user assumptions about auditors...this is a potentially important issue.” Sengupta (2004) examines this issue from an investor-user perspective when he relates the usefulness of a disclosure's information to not only its nature, but also when publicly released (i.e., timing of disclosure as a user-based characteristic).

Our research addresses both practice and academic implications. In its 2004-2009 Strategic Plan the SEC explicitly states as a top priority expanding the list of the types of significant events that may need to be disclosed. Consequently, the first goal of our paper is to use events from prior research to help the SEC in their consideration of expanding their list of events, as well as provide evidence to other regulators (e.g., the IAASB) considering similar actions. This goal is a necessary for helping achieve our paper's other goal: examining the qualitative materiality judgments of one type of financial statement user (nonprofessional investors) to determine if their materiality judgments are driven by information-based characteristics or user-based characteristics. We focus on nonprofessional investors because prior research has shown that this investor classification is a significant market subset and can potentially affect market outcomes (Delong et al., 1989; 1990; 1991; Tuttle et al., 1997). 
Using prior research from the materiality, investor behavior, and psychology literatures to support our predictions, we conduct a series of experimental markets to address the above goals. We find no evidence of an information-based characteristic (distinguishing between SEC listed events and non-listed events) as having an effect on nonprofessional investors' stock price materiality judgments. However, we find evidence that one type of user-based characteristic (anchoring) impacts this judgment. Investors respond more strongly to information disclosed at the beginning of a sequence than information disclosed at the end of the sequence, regardless of its direction or if it is an SEC listed event. We do not find evidence that direction of disclosed events affects investor judgments. Post hoc and sensitivity analyses provide further support for our findings.

The finding that sequence order impacts materiality judgments should be of interest to both managers and regulators. If managers recognize that the order in which disclosures occur can influence user decisions, they can use such knowledge when material events are planned to occur within a firm and must be disclosed to third party users. Consequently, regulators and auditors, as watchdogs for third party users, should be aware of the possibility that managers may abuse this qualitative characteristic and manipulate user behavior.

Our results suggest a need to further heed the calls for user-oriented materiality studies (O’Connor and Collins, 1974; Messier et al., 2005), especially in the qualitative area of disclosure content (i.e., events, as opposed to quantitative materiality thresholds), in order to assist regulators with identifying potentially material events for decision makers. Our research also paves the way for further study of the impacts of information-based characteristics and userbased characteristics on user judgment. The remainder of this paper is organized as follows: 
Section 2 contains the literature review and hypotheses development; Section 3 contains the experimental design; Section 4 contains the empirical results; and Section 5 the conclusions.

\section{Literature Review and Hypotheses Development}

\subsection{Defining Materiality}

The concept of materiality is one of the most pervasive concepts in accounting practice, yet a definitive explication has consistently eluded accounting researchers and practitioners (O’Connor and Collins, 1974; Messier et al., 2005). When materiality is properly applied, financial statements should provide users with all of the available information that would influence their decision making. CON 2 (1980), SAB 99 (1999), and Statement of Auditing Standards (SAS) 107 (2006) indicate that materiality: is a matter of judgment; includes the relevance of both quantitative and qualitative considerations; and is influenced by the perceived needs of financial statement users. Auditor and management materiality judgments regarding potentially material events could benefit from SEC guidance. ${ }^{3}$ However, it is not feasible for the SEC to provide a comprehensive list of potentially material events.

Despite the need for guidelines on materiality (Morris and Nichols, 1984; Jennings et al., 1987), until the recent regulatory interest, none have been developed (i.e., Regulation FD (2000) and the IAASB deliberations). The SEC has traditionally balked at providing a more specific definition when pushed by accounting practitioners and investor groups (Wright and Taylor, 1982). The absence of authoritative guidance means that support for practitioner materiality decisions has come from non-authoritative sources, such as empirical research on materiality judgments of users, preparers, and auditors of accounting information (Holstrum and Messier, 1982). 


\subsection{How Materiality is Determined}

A significant problem concerning materiality involves how the materiality assessments are made. Specifically, who makes the materiality judgment and how does it impact investors' decisions? Materiality is often measured by an auditor's own belief of what is important to investors rather than by a direct assessment of the effect of information on decisions (AbdelKhalik, 1977).

With the exceptions of Cho et al. (2003), Haka et al. (1986), Fisher (1990) and Tuttle et al. (2002), the majority of the existing materiality research has overwhelmingly focused on the auditor’s perspective (e.g., Ward, 1976; Moriarity and Barron, 1979; Steinbart, 1987; Chewning et al., 1989; Morris and Nichols, 1988). While important to investigate and understand, some problems can occur when considering materiality from the auditor's perspective. Previous research indicates users (i.e., investors) have lower materiality thresholds than auditors (Holstrum and Messier, 1982). Further, auditors from the largest public accounting firms generally have higher materiality thresholds than other auditors (Iskandar, 1996). ${ }^{4}$ Although there is some support in the literature for materiality thresholds when the effect on income is less than five percent, the results become unclear when different groups of investors are used (Liu and Mittelstaedt, 2002).

Another problem with primarily focusing on materiality from an auditor's perspective stems from individual users assessing materiality differently than auditors. Studies have investigated the ability of individual investors to identify and/or assess materiality. Patillo $(1975,1976)$ indicates that in the absence of knowledge of management's disclosure (materiality) criteria, investors have applied substantially different criteria (perhaps incorrectly) in their evaluation of financial statements. More recently, Cho et al. (2003) investigate 
investors' perceptions of materiality with regard to the percentage of pretax earnings, percentage of sales and percentage of total assets. Consistent with Patillo's findings, their results suggest that investors use a different materiality level than auditors. Specifically, they find that investors use a lower level of materiality than those used in practice and suggested in pedagogical literature. Further, Tuttle et al. (2002) find that nonprofessional investors do not trade according to standard, quantitative thresholds of materiality employed by auditors.

Besides the issue of primarily studying materiality decisions from an auditor's perspective, a serious problem associated with how materiality assessments are made is allowing management to opportunistically set materiality. According to Libby and Kinney (2000), SEC registrants abuse materiality thresholds by opportunistically misstating earnings by quantitatively immaterial amounts. The same study finds that auditors allow firms to opportunistically apply materiality thresholds. Further, management may decide to withhold their materiality thresholds altogether. In that case, investors have to attempt to "see into the minds of management" to determine what is important (material) in their investment decisions.

Chen et al. (2007) investigate quantitative materiality thresholds. Specifically, they compare a series of SEC mandated financial restatements to conservative benchmarks (five percent of income and one percent of the greater of total assets or revenues), non-conservative benchmarks (10 percent of income and one-and-a-half percent of the greater of total assets or revenues), and tolerable misstatement benchmarks (two-and-a-half percent of income and a half of a percent of the greater of total assets or revenues) using data from the 2003 General Accounting Office database. Their results indicate frequent restatements (i.e., restatements made 15-64 percent of the time) when the incidences causing the restatements are below the auditor 
planning materiality levels. This implies that there are qualitative reasons for the restatements over and above the quantitative nature of the related transactions.

Dezoort et al. (2003) build upon the SEC conclusion in its SAB 99 (1999) - that exclusive reliance on quantitative approaches to assess materiality is not acceptable - by studying audit committee reactions to management-auditor disagreements. The authors (p. 178) state there are no rules or standards for assessing materiality or explaining materiality judgments to constituent groups, and that the quality of auditors' materiality judgments have been heavily scrutinized in recent times. Their findings lead to the suggestion that regulators should require: 1) auditors and audit committees to discuss qualitative aspects of materiality; and 2) greater disclosure of qualitative aspects, such as estimates.

To summarize, there is a demonstrated difference in materiality thresholds between auditing firms of different sizes, auditors and investors, auditors and regulators, and management and investors. According to CON 2's (1980) materiality definition cited earlier and Chen et al.'s (2007) findings, materiality should be based on the impact an event would have on a reasonable investor's decision. However, materiality criteria are not likely to capture the impact desired by nonprofessional investors (our investor sample) because the criteria are based on the beliefs of others (i.e., auditors and management). As a result, investor decisions on firms' financial statements may be negatively impacted. ${ }^{5}$

\subsection{Assessing Materiality Using Characteristics of the Information}

\subsubsection{Listed vs. Non-listed Events}

Patillo (1976) investigates over 51,000 materiality judgments for a combination of stakeholders. He concludes that the type of information/event has a significant impact on materiality determinations. What is not known is 'why?' Understanding what makes 
information material from an information characteristics' perspective is a challenging process. In our study, we consider an information characteristic not previously investigated in the materiality literature: whether the event has been specifically cited by the SEC as one that is likely to be material. Therefore, we extend Patillo's (1976) initial materiality findings in the context of the SEC's most recent Strategic Plan.

The SEC began its "policy" of citing events in its Regulation FD (2000). Indeed, at a Regulation FD roundtable, many of the (management) participants expressed litigation concerns surrounding disclosure materiality judgments (Arya et al, 2005). Regulation FD requires firms to disclose material information through some form of "accepted" media. Examples of acceptable media include: (1) filing the information with the SEC on a Form 8-K; (2) issuing a press release; or (3) providing public access (e.g., by phone access or over the Internet) to the conference call or meeting. FD requires all material events to be made public knowledge either immediately or within one day following disclosure to a "selected" party. When considering materiality, the SEC lists the following events in accordance with FD: earnings information; mergers and acquisitions; new products or developments regarding customers or suppliers; changes in control or in management; change in auditors; events regarding the firm's securities; and bankruptcies or receiverships.

Furthering the process of requiring firms to make material disclosures SOX Section 409 (2002) establishes the need for disclosures to be made "on a rapid and current basis." In response, the SEC issued Release No. 33-8400 (2004), which establishes the following two goals: 1) expand the number of disclosures required to be submitted on the Form 8-K; and 2) decrease the reporting deadline from typically 15 days to only four days after event occurrence. The SEC required the following eight events (in addition to Regulation FD 2000 events) to be 
filed on a Form 8-K: entry into a material definitive agreement; termination of a material definitive agreement; creation of a direct financial obligation or an obligation under an offBalance Sheet arrangement of a SEC registrant; triggering events that accelerate or increase a direct financial obligation or an obligation under an off-Balance Sheet arrangement; costs associated with exit or disposal activities; material impairments; notice of delisting or failure to satisfy a continued listing rule or standard; and non-reliance on previously issued financial statements or a related audit report. The SEC also expanded the scope related to the following events: departure or appointment of directors or principal officers; and amendments to articles of incorporation or bylaws and changes in fiscal year.

Both the SEC Release No. 33-8400 (2004) and Regulation FD (2000) provide guidance to auditors and management regarding potentially material disclosures. However, in total, there are only 15 listed events. Despite the need for additional events as identified in the SEC's most recent Strategic Plan, we acknowledge attempting to provide an exhaustive list is not feasible. Therefore, one goal of our study is to assist the SEC in their attempt to identify additional events. This goal leads to our other goal of examining the effects of information-based characteristics and user-based characteristics on materiality determinations.

We start this process by first clarifying if there is a difference between the SEC's current list of events (i.e., listed) and events not currently listed by the SEC, but used in previous, applicable academic research (i.e., non-listed). The difference between listed and non-listed events is classified as an "information-based characteristic" for future analysis. Our upcoming theoretical hypotheses rely on the user's weighting of the events. If a difference favoring the SEC's current list of events is found, then the weighting of the events would be unequal, presenting evidence of both the significance of an information-based characteristic and a noisy 
confound in our hypothesis testing. Given the relative newness of the SEC's change in "policy" to explicitly list events, there is a lack of appropriate regulatory theory to guide a formal research hypothesis in this area. Therefore, we state this issue in the form of a research question, rather than a formal hypothesis, and use the subsequent statistical results to guide our upcoming hypotheses testing.

\section{RQ1: Do nonprofessional investors' perceive a materiality difference between the SEC's currently listed events and currently non-listed events used in previous, applicable academic research?}

We now consider Schipper's (2007) concern that, perhaps, user materiality decisions are not information-based, but, rather, are specific to the user. Our next section explores this possibility.

\section{4. $\quad$ Assessing Materiality Using Investor Characteristics}

As previously stated, regulator materiality deliberations are made in consideration of the judgments of reasonable users (CON 2, 1980). Research has shown that different classes of decision makers (i.e., investors, auditors, management) assess the materiality of a given event differently. Our research investigates the investment behavior of nonprofessional investors.

The events in our study can only be interpreted as either positive or negative in nature. Events perceived as positive will imply subsequent gain while those perceived as negative will imply a loss to investors. Consequently, we refer to three well researched theories in the decision making literature - negativity bias, loss aversion and anchoring - to explain the investor decision-making process. It is important to note that these theories are useful in explaining investor behavior regardless of whether or not the event is an SEC listed event.

\subsubsection{Negativity Bias}


Comparing the effects of positive and negative information has been extensively investigated in the psychology, accounting, and finance literatures. Psychology research has demonstrated that individuals automatically devote more attention to negative information than to positive information (Smith et al, 2006). The increased attention to negative information has been found to exist in everyday events such as trauma, close relationship outcomes, social network patterns, interpersonal interactions, and learning processes. Further, negative events have been found to have more impact, in general, than positive events, because negative events are processed more thoroughly (i.e., greater persistence of unconscious attention; Baumeister et al, 2001). The greater persistence of increased attention after unpleasant (negative) stimuli compared to pleasant (positive) stimuli is consistent with the existence of a negativity bias (Hajcak and Olvet, 2008).

In an investing context, the negativity bias can be thought of as negative information influencing evaluations of firm disclosures more strongly than comparably extreme positive information. That is, the investor perceives both negative and positive information as approximately "equally extreme," yet the negative disclosures are weighted more heavily in the investing judgment. Ito et al. (1998) find that positive and negative information elicit stronger reactions than neutral information, and negative is stronger than positive even though both are equally probable as to their occurrence, extremity and arousal. Their finding is consistent with similar results indicating negative information more strongly influences people's evaluations than comparably extreme positive information (Skowronski and Carlston, 1989).

Cacioppo et al. (1997) depict the negativity bias as the tendency for a unit of activation to result in a greater change in output for a negative motivational system as compared with a positive motivational system. As a result of the negativity bias, attitudinal and behavioral 
expressions should be more strongly impacted by negative stimuli than positive stimuli (Cacioppo and Berntson, 1994). Relatedly, negativity bias has been used to motivate directional hypotheses in various accounting and finance contexts. For example, Kadous et al. (2007) predict and find evidence indicating that investors react more strongly to negative information regarding analysts' credibility than to positive analyst credibility information.

\subsubsection{Loss Aversion}

Individuals report greater distress over losses than they do for gains of equal magnitude. This behavior is referred to as loss aversion. Specifically, loss aversion refers to the tendency for individuals to be more sensitive to reductions in their levels of well being than to increases.

The notion that individuals treat gains and losses differently has a long tradition. The concept of loss aversion has been applied across various domains including labor economics, consumer goods macro-economics and the stock market. For example, Benartzi and Thaler (1995) show that more frequent evaluations of portfolios lead to lower evaluations generated by investors. Since investors weight negative returns (losses) more heavily than positive returns (gains), their evaluations are adversely affected by a larger number of negative returns as opposed to positive returns. Additionally, Shefrin and Statman (1985) predict that people dislike incurring losses so much more than they like incurring gains that they would be willing to gamble in the domain of losses. Typically, investors will hold on to stocks that have lost value too long and sell stocks that have risen in value. This is called the disposition effect. Thus, not only does loss aversion describe how individuals distress over losses and gains in their welfare, it also serves as a platform from which other adverse behaviors can manifest.

To summarize, multiple theories suggest that individuals will react more strongly to negative/loss situations relative to equally positive/gain situations. In our research setting, the 
nonprofessional investors should weight disclosures containing negative events more so than they do disclosures containing positive events. With regard to investor materiality, negative events would more likely be perceived as material than the positive events. Thus, our first hypothesis is stated:

\section{H1: Nonprofessional investors are more likely to treat disclosures of negative events as material than they are disclosures of positive events.}

\subsubsection{Anchoring}

Another user characteristic that could impact nonprofessional investors' decisions could be the length of the sequence of events presented to them. Stated differently, it is possible that investors may perceive events at the beginning of the sequence differently from those at the end of the sequence, especially if investors are faced with a long series of events over time. We now turn to the belief revision literature to explain expected nonprofessional investor behavior in this context.

Tversky and Kahneman (1974) are the first to identify and label the anchoring heuristic as a way individuals make decisions. When anchoring is used, an initial estimate called an "anchor" is followed by an insufficient adjustment as more information is presented (Butler, 1986). Typically, adjustments are made in the appropriate direction, but are insufficient to bring the revised belief to the "correct" value - the value that would have been obtained if anchoring had not occurred (Kinney and Uecker, 1982). Conversely, the anchor-and-adjustment heuristic involves a sufficient enough adjustment to form a revised belief significantly different from the previous anchor (Hogarth and Einhorn, 1992) In our research context, if a disclosure contains "material” information, a sufficient anchor-and-adjustment should occur; however, if an insufficient adjustment occurs the anchoring heuristic is predicted to be used. 
“Across an ever-expanding number of domains, research has shown that people's judgments of uncertain quantities are biased in the direction of a salient comparison value or anchor,” (Epley and Gilovich, 2005, 200). In the accounting literature, Joyce and Biddle (1981) find anchoring effects among students and experienced participants (auditors) when assessing direct risk. ${ }^{6}$ Kinney and Uecker (1982) also use experienced auditors and find that they anchor on the sample error rate given. Using the same type of participants, Butler (1986) discovers that experienced auditors develop an internal reference point and anchor on that when making riskbased decisions. Indirectly related to risk, $\operatorname{Ng}(2007,74)$ reports that previous audit research (e.g., Wright, 1988; Tan, 1995) finds that auditors anchor on prior year information when making current year judgments. Hobson and Kachelmeier (2005) manipulate disclosures of the expected value of a risky proposition in a market setting. They find evidence of the anchoring heuristic, even when there are economic incentives to behave otherwise.

Except for the Butler (1986) study, all of the previously cited studies provide an anchor to the participants. Kahle et al. (2005) indicate that auditing research has found different results depending on how the anchor is formulated. According to Epley and Gilovich $(2005,202)$, “...self-generated (internal) anchors differ from those in the standard anchoring paradigm (i.e., externally-provided anchors) because they are known from the beginning to be wrong and thus do not need to be considered as possible answers to the target question. They therefore do not activate the same selective accessibility mechanisms that novel 'experimenter-provided' anchors do, but instead initiate a process of effortful serial adjustment that modifies the initial anchor in a direction that seems appropriate until a plausible estimate is reached.” Epley and Gilovich also: 1) find evidence that internal anchors are more influenced by (financial) incentives than externally-provided anchors; and 2) indicate that adjustment requires mental effort individuals 
may be either unwilling or unable to expend resulting in insufficient adjustments from the applicable anchor.

Although the applicable literature does not state the number of cues needed for the individual to form a "strong enough" internal anchor such that the anchoring heuristic is used, we believe that at the beginning of the experimental market the likelihood of financial gain is especially salient to the participants. Therefore, they are likely to perform sufficient anchor-andadjustments (i.e., revised beliefs significantly different from their prior anchor) while trading to assure themselves of profit. Once reaching a satisfaction level with respect to desired profit, they should stop trading (do not provide as much "effort" to the task, while reducing the sufficiency of their adjustments) so as not risk losing what has been "won.” A less active market results and less "material" stock price changes follow. This predicted effect is supported by Tversky and Kahneman's (1974) anchoring findings previously cited. Additionally, our design choice of a long series of disclosures (simulating a more realistic disclosure environment for a large firm) lends itself to reduced mental effort over time as the participants could become fatigued.

Our second hypothesis is now stated:

\section{H2: Given a long sequence of disclosures, nonprofessional investors are more likely to treat initial disclosures as material than disclosures later in the sequence. ${ }^{7}$}

\section{Methodology}

O’Connor and Collins (1974) suggest research on the predictive ability and the information content of accounting data (i.e., what we have termed "information characteristics”) has direct implications to a user-oriented materiality. This type of research concentrates on discrete events (e.g., earnings announcements), rather than on a continuous event whose impact can be assessed by its strength. Our research design expands the notion of "accounting data” to 
include nonfinancial events, because Regulation FD (2000) and SEC Release No. 33-8400 (2004) significantly add this category of events to their lists.

Prior quantitative materiality research uses income as a relative measure of materiality. However, we do not use this approach because of certain limitations. Prior research shows that the selection of accounting methods (e.g., depreciation method, inventory method, etc.) directly affects the measurement of income; thereby, making between-firm materiality comparisons difficult (Morris and Nichols, 1988). Shafer (2002) uses an 11-point scale for the manipulation check, rating the materiality misstatement from immaterial to highly material. Although we measure the scaled importance of weightings, we use the actual behavior (i.e., stock price judgments) as the proxy for potential materiality. Testing potential materiality in terms of trading behavior is consistent with Kinney et al.'s (2002) design and prevents the implicit assumption that cue weightings correlate $100 \%$ with trading behavior (i.e., higher weighted cues will always result in increased trading behavior in the direction of the cue), when that may not be the case. ${ }^{8}$

\section{1. $\quad$ Procedure}

We use a series of experimental markets to test our research question and hypotheses. Our experimental procedure is adapted from Tuttle et al.'s (1997) methodology; therefore, we only provide the following limited description. Experimental markets are conducted using Financial Trading System software developed by The Wharton School of the University of Pennsylvania. ${ }^{9}$ Each experimental session consists of three rounds of trading involving a fictitious company named "Autismo." Multiple traders could make and accept bids and offers for shares of stock or have the choice of standing pat with the shares and money they currently own. 
Instructions are distributed at the beginning of each experimental session. Traders are told that each round (consisting of multiple periods of stock trading) is independent of all other rounds. At the beginning of each multi-period round, each trader receives 60 lab dollars (30 of which is an interest free loan to be repaid at the end of the round) and six shares of Autismo's stock. Traders are also provided the information in table 1 , which shows possible liquidating dividends at the end of each round, as well as associated probabilities of each dividend. Based on the possible dividends and probability distribution shown in the table, the expected value of the liquidating dividend is 12 lab dollars per share. Since there is only a $30 \%$ likelihood of the 12 dollar liquidating dividend, and a wide distribution of other potential liquidating dividend amounts, the participants are allowed to create their own internal anchors. At the end of each round, lab dollars are converted to cash payoff at an exchange rate of \$.5 US equal to10 lab dollars. ${ }^{10}$

[Insert table 1 about here]

Each trading period within a round lasts three minutes. Before each trading period, a disclosure involving Autismo is publicly announced, both verbally and via computer projection in front of the lab. After the disclosure, traders are given time (approximately 10 to 15 seconds) to rate their perceived importance and direction of the item on a scale from -10 (very important bad news) to 10 (very important good news). A similar 21-point scale is used in Tan et al. (2002) and Pinsker (2007) to account for the variation of responses. After all traders have completed their disclosure rating, the trading period begins. Each trade is only for one share of stock; however, traders can buy and sell multiple times in a trading period as long as another willing trader exists. At the end of each round, the liquidating dividend is announced and profits are calculated. ${ }^{11}$ 
The first round of trading is a practice session, lasting two trading periods. This time is spent learning the software and answering questions about the mechanics of the market. In one experimental session of 30 traders (henceforth, order 1), after the practice round, the first round is 20 trading periods in length and the second round is four periods. That is, the first round consists of 20 firm disclosures and the second round consists of four firm disclosures. In two other experimental sessions of 9 and 13 traders (22 in total), respectively (henceforth, order 2), the first round is four periods in length and the second round was 20 periods. The differing numbers of periods per round are based on the dichotomy of short (16 or less) vs. long (17 or

more) series of reporting periods (as defined by Hogarth and Einhorn, 1992; see footnote \#7) and are designed specifically for the user characteristics' hypotheses. Rounds are reversed from the first to the second and third sessions to control for order effects. Traders are told beforehand that only activity from the second and third rounds (i.e., not the practice round) is considered when

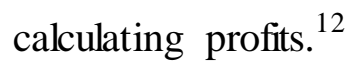

\subsection{Variables}

\subsubsection{Dependent Variable}

A disclosure is deemed "material" either if the 'disclosure number' independent variable is significant in the ANOVA (in the correct direction) and agrees with the Kruskal-Wallis (KW) results or if the KW results are significant (when there is a disagreement between parametric and non-parametric results) and in the correct direction. ${ }^{13,} 14$

\subsubsection{Independent Variables}

The 'trader identifications' (both of the trade initiator and acceptor) serve as the withinsubjects variables. The 24 disclosures from the non-practice rounds consist of event types listed in SEC Release No. 33-8400 (2004), Regulation FD (2000), or are not currently listed by the 
SEC, but have been used in prior related research (Pinsker, 2007; see table 2), with eight items for each event type. Thus, our manipulation for RQ1 is at three levels. The event types are not disclosed to participants. The eight items per type consist of four positive items and four negative items and are the result of extensive pilot testing. ${ }^{15}$ Table 2 displays the event type and describes each event as positive or negative for the purposes of testing RQ1 and H1.

[Insert table 2 about here]

\subsection{Participants}

The target group for our experimental market is nonprofessional investors. We choose this investor group, because: 1) prior research has shown that this investor classification is a significant market subset and can potentially affect market outcomes (Delong et al., 1989; 1990; 1991; Tuttle et al., 1997); and 2) as previously stated, we believe this group is inclusive to CON 2’s (1980) "reasonable user" determination. Our participants are upper-division, undergraduate accounting students who have completed the first intermediate accounting course. Our choice of participants is consistent with the prior research from which our design is based (i.e., Tuttle et al., 1997; Pinsker, 2007).

After completing the experimental market, participants provide a variety of demographic data. In aggregate, 52 students volunteer for the market sessions (27 males and 25 females) with a mean (standard deviation) age of 21.87 (2.79) years. The mean (standard deviation) number of college semesters completed at the time of the experimental session attended is 6.43 (1.76). The participants have worked a mean (standard deviation) of $3.20(2.68)$ years. ${ }^{16}$

Participants submit answers to two questions regarding their level of investment knowledge and experience, on a scale of 1 (low) to 7 (high). The mean (standard deviation) participant investment knowledge is 3.71 (1.46) and the mean (standard deviation) investment 
experience is 2.53 (1.64). Comparisons of these means to a score of 4 (neutral) show that, on average, participants perceive themselves as having low levels of investment knowledge and experience. Similar self-reported knowledge and experience scores are present in Pinsker's (2007) study of nonprofessional investor behavior. Aggregate participant responses to our demographic questions indicate a closeness of our participants to the group of nonprofessional investors described in Ritt's (2004) listed demographics of the "average American investor." "17

\section{4. $\quad$ Results}

\subsection{Preliminary Analysis}

Participants receive a different order of disclosures depending on which session they attend. An ANOVA indicates the mean stock price does not differ significantly between groups $(F=0.43, p$-value $=0.65)$. Consistent with the discussion of the demographic data in the previous section, these data suggest that the participants are homogenous across treatments.

The disclosure ‘direction’ manipulation is tested using disclosure weightings requested during the experimental market sessions. The disclosure means (standard deviations) as well as the intended disclosure direction are shown in table 3. For each disclosure, parametric t-tests as well as non-parametric Mann-Whitney and Kolmogorov-Smirnov tests are conducted to determine if mean responses are significantly greater than zero. Test results are significant at $p$ value $<0.01$ and the means are in the expected direction for all disclosures, indicating the 'direction' manipulation is successful. ${ }^{18}$

[Insert table 3 about here]

Since sessions two and three use the same order of disclosures and do not have any statistically significant demographic differences, their data is combined for hypothesis testing. Figure 1 is presented as a way to visualize the data. 
[Insert figure 1 about here]

\section{2. $\quad$ Main Results}

Mean (standard deviation) stock prices and the absolute value mean differences in stock price for each disclosure and each order are presented in table 4. The mean stock price is the average stock (contract) price for that disclosure in the specific experimental session. There are 16 possible material disclosures for each event type (i.e., eight each from Regulation FD, 2000, SEC Release No. 33-8400, 2004 and non-listed for two orders), or 48 in total. When the two orders are examined in the aggregate (i.e., 16 disclosures for each event type), seven Regulation FD disclosures, 11 SEC Release No. 33-8400 disclosures, and nine non-listed disclosures are deemed "material” by our nonprofessional investor participants (see table 4).

[Insert table 4 about here]

\subsubsection{Research Question 1}

We test RQ1 by using a logistic regression and two-way Chi-square test where the premise is the likelihood of one event type (i.e., Regulation FD, 2000, SEC Release No. 33-8400, 2004, or non-listed) being more material than another. A logistic regression is appropriate when both dependent and independent variables are categorical and no cell size is below five (both criteria apply to our sample; Mendenhall and Sincich, 1996). The two-way Chi-square test is used for robustness purposes. 'Materiality' (a dummy variable where $0=$ no and $1=$ yes; see earlier discussion under "Variables" and table 4 for materiality determination information; this is the same coding for the following hypothesis testing as well) is the dependent variable and ‘event type’ (dummy variables representing Regulation FD, SEC Release No. 33-8400, and nonlisted) is the independent variable. ${ }^{19}$ 
RQ1 considers if nonprofessional investors are more likely to treat SEC listed events, relative to non-listed events, as material. The logistic regression result indicates no statistical differences between event types $\left(\chi^{2}=1.22, p\right.$-value $\left.=0.54\right)$. The two-way Chi-square result reaches the same conclusion $\left(\chi^{2}=2.18, p\right.$-value $\left.=0.34\right)$. All possible two-way comparisons have also been examined with our conclusion remaining unchanged - nonprofessional investor participants appear to incorporate both SEC listed and non-listed events into their judgments. Therefore, either the currently listed events are not relatively more important to our user group or, following further study, the SEC should consider the non-listed events we use in future event deliberations (since they are of statistically "equal" weighting). ${ }^{20}$

\subsubsection{Hypothesis 1}

Hypothesis 1 incorporates the negativity bias and loss aversion theories to predict that disclosures containing negative event information will be more likely to be material than are disclosures containing positive event information. In accordance with the events listed in table 2, we coded positive events with a 1 and negative events with a 0 . We then ran a logistic regression using this dummy variable and 'materiality.' Our results indicate that disclosures containing negative events are not more likely to be material than are disclosures containing positive events $\left(\chi^{2}=2.13, p\right.$-value $\left.=0.14\right) .{ }^{21}$ Thus, we conclude that disclosure direction is not a critical component to materiality among our investor proxy and, therefore, $\mathrm{H} 1$ is not supported.

\subsubsection{Hypothesis 2}

H2 predicts that for a long series of disclosures nonprofessional investors will initially have a weak internal anchor for the earlier disclosure events making them more likely to be material (due to anchor-and-adjustment) than are events later in the disclosure sequence (due to anchoring on a relatively stronger anchor). In order to be consistent with the recent literature 
(i.e., Favere-Marchesi, 2006), as well as predominate methodology of choice in the vast belief revision prior literature (see Kahle et al.'s, 2005 review), we conduct our tests comparing the first five disclosures to the last five disclosures in the 20 disclosure sequence only. ${ }^{22}$ Use of the first five events is consistent with the prior anchoring citations, which use four items (two positive and two negative) in testing potential belief revision. Our first disclosure begins to establish the internally-generated anchor and the four consequent disclosures (two each of statistically equal strength and direction) allow for either an anchoring or anchor-and-adjustment phenomenon to occur. The insignificant finding for RQ1 provides evidence that the perceived strength/weight of the 20 disclosures does not vary significantly. This finding lends further credence that if the predicted effects are found, they are likely due to user characteristics, rather than information characteristics.

Descriptive results show that nine-of-10 disclosures in the first sequence of five (for both orders) are deemed material by our nonprofessional investor sample. This result is compared to only five-of-10 disclosures in the last sequence of disclosures. Results from a logistic regression comparing the sequences of five disclosures as independent variables and the 'materiality' dependent variable statistically support our descriptive findings. Specifically, the first sequence of five disclosures are more likely to be treated as material than the last sequence of five disclosures $\left(\chi^{2}=4.07, p\right.$-value $\left.=0.04\right)$. Therefore, we can now provide evidence that the anchoring user characteristic affects nonprofessional investors' materiality judgments later in the disclosure sequence and $\mathrm{H} 2$ is supported. ${ }^{23}$ Table 5 summarizes the results from our research question/hypothesis testing.

[Insert table 5 about here]

\subsection{Post Hoc Analysis}


Given the predictions and prior support found in the literature for negativity bias and loss aversion, it is possible that our participants reacted differently to negative Regulation FD (2000), SEC Release No. 33-8400 (2004), and non-listed disclosures than to positive examples of those event types. To test this notion, a ‘direction’ (positive or negative) main effect and interaction term (i.e., 'direction $\mathrm{x}$ event type') is inserted in retesting RQ1. When incorporating these changes, all results remain unchanged ( $p$-value $>0.10$ in all cases, including the new variables). Therefore, we conclude that the direction of the event types has no statistical effect on our participants.

\subsection{Sensitivity Analysis}

As shown in table 4, not all mean prices are in the desired direction (i.e., not all intended positive disclosures increase in price relative to the previous disclosure and not all intended negative disclosures decrease in price relative to the previous disclosure). In order to provide further support for our results, we retest excluding the disclosures that would have been deemed "material" if not for the opposite directional effects as intended. The following disclosures fit this description: disclosure \#7 (order 1), 12 (order 2), and 24 (order 2). After removing these disclosures, our main experimental market results remain unchanged. Thus, even though the 'direction' manipulation appears unsuccessful for these disclosures, it does not affect the inferences we can make regarding our results. ${ }^{24}$

\section{Conclusion}

When the SEC began listing specific potentially material events in its Regulation FD (2000) and in its Release No, 33-8400 (2004), it deviated from its long-time "policy" of not providing materiality guidance to auditors and managers. What is currently unclear in the 
materiality literature is which factor(s) - information-based characteristics or user-based characteristics - has an effect on user (e.g., nonprofessional investor) qualitative materiality judgments. We review the applicable materiality, investor behavior, and psychology literatures to predict two user-based effects on the materiality judgment behavior of a nonprofessional investor proxy. Using a series of experimental markets, we also examine nonprofessional investors' judgments by comparing SEC listed events and non-listed events in order to assist the SEC in identifying additional potentially material events. Our investigation is different from the previous materiality studies in that we consider the (qualitative) nature of the event, rather than simply its (quantitative) magnitude.

We find no evidence of an information-based characteristic (distinguishing between listed and non-listed events) or one of the user-based characteristics (direction of disclosed events) as having an effect on nonprofessional investors’ materiality judgments. However, we find evidence that one type of user-based characteristic (anchoring) impacts this judgment. Post hoc and sensitivity analyses provide further support for our findings.

Our results have several implications in academia and in practice. We find significant effects of anchoring later in a sequence, which implies that the content of the information disclosed to nonprofessional investors may not be as important to this group as when it is disclosed (complementing Sengupta’s, 2004 argument). Information disclosed at the beginning of the sequence was reacted to generally in a greater manner than information disclosed at the end of the sequence regardless of direction, whether it was an SEC listed event or not. This finding should be of interest to a number of groups concerned with disclosing material events. Managers should understand that the sequence of disclosures can impact a third party user's reaction to those disclosures. Managers can consider this factor when planning and making 
decisions within operations that must be disclosed publicly. However, managers can abuse this finding and take the opportunity to manipulate the reaction by users. For this reason, regulators, auditors and users should be aware of the possibility of the manipulation of the sequence of disclosures for the purpose of managing user decisions.

Our results suggest a need to further heed the calls for user-oriented materiality studies (O’Connor and Collins, 1974; Messier et al., 2005), especially in the qualitative area of disclosure content (i.e., events, as opposed to quantitative materiality thresholds), in order to assist regulators in identifying potentially material events for decision makers. Altogether, research findings are in agreement with the quotation made at the beginning of the paper and suggest more focus on qualitative aspects of disclosures.

Our research is limited in that participants in our experimental setting only had information regarding the event in question. Investors often have more information when assessing stock value. However our design allows for control of other external factors that could impact judgments (e.g., economic upturns and downturns, fluctuations in interest rates, etc.). Although the number of disclosures used is consistent with Hogarth and Einhorn's (1992) short series vs. long series dichotomy, the actual number chosen is arbitrary. Additionally, we did not find any evidence of a commitment to the first disclosure in a sequence (hence, a "strong" anchor). Yet we cannot rule out the possibility that our design incorporating alternating, directional pairs of disclosures created indecision in the participants' minds causing them to form weak anchors (as an alternative explanation to our second hypothesis' development).

Several future research opportunities exist. For instance, we investigate nonprofessional investor behavior (e.g., upper-division accounting students). Even though nonprofessional investors represent a sizable percentage of the investing population, future research should 
examine how sophisticated investors (e.g., analysts) make qualitative materiality judgments. Additionally, we chose investors as our financial statement user example. Future research should consider the reactions of other users (e.g., banks and other financial institutions). Despite investigating the anchoring heuristic in the context of anchor-and adjustment (to determine if the adjustment is sufficient enough to categorize a disclosure as "material"), we do not proceed to the next logical step in belief revision theory relating to order effects. Future research should investigate the relationship between observed anchoring in various locations of an information sequence and the persistence of specific order effects. Finally, we are unable to theoretically provide an explanation as to which types of events the SEC should consider listing. Future research should continue to explore this issue as well as design a study that examines the nonmateriality impacts of SEC listed versus non-listed events. 


\section{Footnotes}

${ }^{1}$ Former SEC Deputy Chief Accountant Scott Taub documents several instances where quantitatively "large” errors were deemed as "immaterial” by the SEC (Taub, 2007).

2 The Financial Accounting Standards Board's (FASB) Statement of Financial Accounting Concepts No. 2 (CON; FASB, 1980) defines materiality as "the omission or misstatement of an item is material in a financial report if, in light of surrounding circumstances, the magnitude of the item is such that it is probable that the judgment of a reasonable person relying upon the report would have been changed or influenced by the inclusion or correction of an item." SAB 99 (1999) has a similar definition. The SEC has traditionally balked at providing exact materiality guidelines to accounting practitioners, whether they are quantitative or by event type (Iskandar, 1996).

${ }^{3}$ In CON 2 (1980, paragraph 131), the FASB acknowledges that materiality guidance is sometimes needed. Guidance also addresses the needs of the FD (2000) commenters' requests previously mentioned.

${ }^{4}$ Pany and Wheeler (1989) find that among the rule-of-thumb materiality measures, sizable differences occur depending upon the method and industry.

${ }^{5}$ Holstrum and Messier $(1982,48)$ describe three main problems with a user approach to materiality (the "user" in our paper is the investor). First, little is known about how financial statement information is utilized in investor decision-making. Second, materiality decisions are made by preparers, auditors, and users; and these heterogeneous groups are likely to have dissimilar views of materiality due to different incentives. Third, there is little information on how materiality standards made by others (the SEC and IAASB in our case) affect users' decisions. Despite the considerable materiality research conducted since Holstrum and Messier's literature review, these same three problems from a user perspective continue to be relevant today (Messier et al., 2005).

${ }^{6}$ Butler (1986) notes that the probability elicitation method used may cause different initial values (i.e., anchors) to be used. Our experimental market controls against this possibility.

${ }^{7}$ Consistent with Hogarth and Einhorn's (1992) dichotomy, a "long series" is one containing 17 or more cues. See the explanation in the "Method" section for more details.

${ }^{8}$ Indeed, for many disclosures, higher cue weightings did not result in a potentially material disclosure and vice versa for lower-rated disclosures.

${ }^{9}$ The university at which our markets are conducted has a site license for the software.

10 The mean payouts for the three experimental sessions are as follows: $\$ 10.77, \$ 10.80$, and $\$ 10.69$ (in order of session occurrence). There are no significant differences between any of the sessions ( $p$-value $>0.90)$. 
${ }^{11}$ As will be discussed in more detail later, there are an equal number of positive and negative disclosures for each round. Therefore, consistent with Tuttle et al. (1997), we deem a net offset of all disclosures against one another.

${ }^{12}$ The twelve positive (negative) disclosures are paired through random assignment. The pairs are then randomly ordered in alternating fashion between positive and negative (or vice versa) disclosure pairings over the two non-practice rounds. For example, the first round of 20 periods in the first experimental market (order 1) begins with two positive followed by two negative disclosures and then alternates back and forth between pairs of positive and negative disclosures. The second round of four periods begins with two negative disclosures followed by two positive disclosures. The second and third experimental markets (order 2) reverse the order of pairings. This practice is consistent with Tuttle et al.'s (1997) methodology.

${ }^{13}$ Levene's test for equal variances shows significant results for the stock price dependent variable in a majority of disclosures. Additionally, probability plots, histograms, and the Kolmogorov-Smirnov statistic with a Lilliefor's correction indicate deviations of univariate normality in all disclosures. Given the departures of the ANOVA normality and equal variance assumptions, we analyze materiality using both parametric and nonparametric tests and rely on the results of the latter test when both tests disagree with regard to statistical significance (consistent with Mendenhall and Sincich’s, 1996 recommendation).

${ }^{14}$ For the first disclosure in a period (i.e., the first disclosure in the short series and long series), there is no established equilibrium market price to use as a basis for comparison. As a result, we assess materiality by comparing the mean stock/contract price to the most likely liquidating dividend known to all traders (i.e., \$12) using $t$-tests. Since this does not represent an equilibrium price, our assessment of materiality does not take into account the direction of the mean contract price for the related disclosures when assessing materiality. However, sensitivity tests conducted using ANOVA, KW, two-way Chi-square, and logistic regression (identical tests as those used in our hypothesis testing) indicate no difference in conclusions reached when removing all $t$-test disclosures from the analysis.

${ }^{15} 60$ upper-division accounting students from a university different from where the markets are run participate in the pilot testing. They rated an initial grouping of 44 potential disclosure items (approximately 15 per event type) on the same 21-point scale that is used by actual experimental participants. Ultimately, the 24 information items that are used in the markets are chosen based on the relative equality of their ratings with other items selected (i.e., higher "strength" ratings, with lower rating variation), and so an equal number of positive and negative items from each category (four) are used.

${ }^{16}$ Consistent with Hunton and Beeler (1997), we ask the participants three questions regarding their self-efficacy of valuing stock prices (i.e., how good they are at valuing stocks; how capable they are of estimating prices; and their ability to value stock prices). There are no differences between experimental sessions for self-efficacy, age, investment knowledge, investment experience, or gender. 
${ }^{17}$ In addition to being paid based on their trading profits, participants also receive extra credit by their instructors. After the experiment, participants answer two questions on a scale of 1 (low) to 7 (high) regarding how earning money and receiving extra credit motivate them to participate and do their best. Sample means are higher than the midpoint of the scale for all sessions ( $p$ values < 0.03). Responses to these questions provide evidence that participants are highly motivated to performing their best.

${ }^{18}$ We ask the participants two manipulation check questions regarding both the number of periods in a round and their order in the experimental session. The first question asks for participant agreement with having first completed (after the training round) a round of four periods followed by a round of 20 periods, while the second question asked for their agreement with the reverse order. Both questions are on a scale of 1 (strongly disagree) to 7 (strongly agree). All mean responses are significant at a $p$-value $<0.05$ in the correct direction. These results indicate that participants have generally paid attention and are aware of the conditions in the experimental market.

19 There is no basis for us to assume that investors will react to all listed events in essentially the same fashion. Therefore, despite both being listed by the same body (i.e., the SEC), we separate Regulation FD (2000) and SEC Release No. 33-8400 (2004) events in our testing. This practice also keeps the sample size constant at eight for each event type.

${ }^{20}$ Unless otherwise noted, all KW results agree with the ANOVA results. Consistent with Kinney et al. (2002), we also calculate the dependent variable as the absolute value of mean differences in stock price for each event type. The premise for these tests is to examine if one or more event type is "more material" than another type. Statistical results agree with the main analysis finding of no difference $(F=0.03, p$-value $=0.97)$.

${ }^{21}$ We also conduct a two-way Chi-square analysis. The results agree with those from the logistic regression $\left(\chi^{2}=2.12\right.$, $p$-value $\left.=0.15\right)$.

${ }^{22}$ We do not use the disclosures in the "short," four disclosure sequence for two reasons: 1) a new equilibrium price is established in this sequence that is independent of the 20 disclosure sequence; and 2) the literature is clear in expressing that only two items (of the same direction) are typically not sufficient information from which to anchor on.

${ }^{23}$ Two-way Chi-square tests confirm the logistic regression results $\left(\chi^{2}=3.81\right.$, $p$-value $\left.=0.05\right)$. In order to provide evidence that our findings are not driven by our design, we also compare the first five disclosures to the next five disclosures in the respective sequence (i.e., disclosures numbered six through 10; this is an admittedly arbitrary choice of disclosures not as supported in the literature as our main design). Results and consequent inferences do not materially change.

${ }^{24}$ The following disclosures in orders 1 and 2 have resulting mean stock prices in the opposite direction as intended and are not deemed to be "material" for hypothesis testing purposes: disclosure \# 6 (order 1), 11 (order 1), 23 (order 1), 6 (order 2), and 16 (order 2). The potential lack of materiality of the mean prices may be due to systematic errors caused by the standard 
deviations in price. Since these disclosures are not deemed "material" anyway, direction is not a concern and further testing is not needed. 


\section{REFERENCES}

Abdel-Khalik, R. A, 1977. Using sensitivity analysis to evaluate materiality. Decision Sciences 8, 616-629.

American Institute of Certified Public Accountants, June 30, 2006. Statement of Auditing Standards No. 107.

Arya, A., Glover, J., Mittendorf, B., Narayanamoorthy, G., 2005. Unintended consequences of regulating disclosures: The case of Regulation Fair Disclosure. Journal of Accounting and Public Policy 24, 243-252.

Baumeister, R. F., Bratslavsky, E., Finkenauer, C., 2001. Bad is stronger than good. Review of General Psychology 5, 323-370.

Benartzi, S., Thaler, R., 1995. Myopic loss aversion and the equity premium puzzle. Quarterly Journal of Economics 110, 73-92.

Butler, S. A., 1986. Anchoring in the judgmental evaluation of audit samples. The Accounting Review 61 (1) (Jan.), 101-111.

Cacioppo, J. T., Berntson, G. G., 1994. Relationship between attitudes and evaluative space: A critical review, with emphasis on the separability of positive and negative substrates. Psychological Bulletin 115, 401-423.

, Gardner, W. L., Berntson, G. G., 1997. Beyond bipolar conceptualization and measures: The case of attitudes and evaluative space. Personality and Social Psychology Review 1, 3-25.

Chen, H., Pany, K., Zhang, J., 2007. An analysis of the relationship between accounting restatements and quantitative benchmarks of audit planning materiality. Presented at the 2007 American Accounting Association Annual Meeting, Chicago, IL.

Chewning, Jr., E.G., Pany, K., Wheeler, S., 1989. Auditor reporting decisions involving accounting principle changes: Some evidence on materiality thresholds. Journal of Accounting Research 27, 78-96.

Cho, S., Hagerman, R. L., Nabar, S., Patterson, E. R., 2003. Measuring stockholder materiality. Accounting Horizons 17 (Supplement), 63-76.

DeLong, J., Shleifer, A., Summers, L., Waldman, R., 1989. The size and incidence of the losses from noise trading. Journal of Finance 44, 681-696.

markets. Journal of Political Economy 98, 703-738 
., 1991. The survival of noise traders in

financial markets. Journal of Business 64, 1-19.

DeZoort, F. T., Hermanson, D. R., Houston, R. W., 2003. Audit committee support for auditors: The effects of materiality justification and accounting precision. Journal of Accounting and Public Policy 22, 175-199.

Epley, N., Gilovich, T., 2005. When effortful thinking influences judgmental anchoring: Differential effects of forewarning and incentives on self-generated and externally provided anchors. Journal of Behavioral Decision Making 18, 199-212.

Favere-Marchesi, M., 2006. "Order effects” revisited: The importance of chronology. Auditing: A Journal of Practice and Theory 25 (1) (May), 6983.

Financial Accounting Standards Board, 1980. Qualitative Characteristics of Accounting Information. Statement of Financial Accounting Concepts No. 2, FASB, Stamford, CT.

Fisher, M. H., 1990. The effects of reporting auditor materiality levels publicly, privately, or not at all in an experimental setting. Auditing: A Journal of Practice and Theory 9, 184-223.

Hajcak, G., Olvet, D. M., 2008. The persistence of attention to emotion: Brain potentials during and after picture presentation. Emotion 8, 250-255.

Haka, S., Friedman, L., Jones, V., 1986. Functional fixation and interference theory: A theoretical and empirical investigation. The Accounting Review 61 (3), 455-474.

Hobson, J. L., Kachelmeier, S. J., 2005. Strategic disclosure of risky prospects: A laboratory experiment. The Accounting Review 80 (3) (July), 825-847.

Hogarth, R. M., Einhorn, H. J., 1992. Order effects in belief updating: The belief -adjustment model. Cognitive Psychology 24, 1-55.

Holstrum, G. L., Messier, W. F., 1982. A review and integration of empirical research on materiality. Auditing: A Journal of Practice and Theory 2, 4563.

Hunton, J.E., Beeler, J. D., 1997. Effects of user participation in systems development: A longitudinal field experiment. MIS Quarterly 21 (4), 359-388.

International Federation of Accountants, 2006. Agenda item 9: Materiality and misstatements. Main agenda presented at the IAASB meeting, Brussels, Belgium. 
Iskandar, T. M., 1996. Industry type: A factor in materiality judgments and risk assessments. Managerial Auditing Journal 11 (3), 4-8.

Ito, T. A., Larsen, J. T., Smith, N. K., Cacioppo, J. T., 1998. Negative information weighs more heavily on the brain: The negativity bias in evaluative categorizations. Journal of Personality and Social Psychology 75, 887-900.

Jennings, M., Kneer, D. C., Reckers, P., 1987. Reexamination of the concept of materiality: View of auditors, users, and officers of the court. Auditing: A Journal of Practice and Theory 6, 104-116.

Joyce, E. J., Biddle, G. C., 1981. Anchoring and adjustment in probabilistic inference in auditing. Journal of Accounting Research (Spring), 120-145.

Kadous, K., Mercer, M., Thayer, J., 2007. Is there safety in numbers? The effects of forecast accuracy and forecast boldness on financial analysts; credibility with investors. Presented at the AAA Annual Meeting, Chicago, IL.

Kahle, J., Pinsker, R., Pennington, R., 2005. Belief revision in accounting: A literature review of the belief-adjustment model. Advances in Accounting Behavioral Research 8, 1-40.

Kahneman, D., Tversky, A., 1984. Choices, values, and frames. American Psychologist 39, 341 $-350$.

Kinney, W. R., Uecker, W. C., 1982. Mitigating the consequences of anchoring in auditor judgments. The Accounting Review 57 (1), 55-69.

-------------., Burgsthaler, D., Martin, R., 2002. Earnings surprise "materiality" as measured by stock returns. Journal of Accounting Research 40 (5), 1297-1329.

Levitt, A., 1998. The numbers game. Remarks delivered by Chairman Arthur Levitt, Securities Exchange Commission at the NYU Center for Law and Business, New York, NY.

Libby, R., Kinney, W. R., 2000. Does mandated audit communication reduce opportunistic corrections to manage earnings to forecast? The Accounting Review 75 (4), 383-404.

Liu, C., Mittelstaedt, H. F., 2002. Materiality judgments and disclosure of retiree health care costs under SFAS No. 81. Review of Accounting Studies 7, 405-434.

Mendenhall, W., Sincich, T., 1996. A Second Course in Statistics: Regression Analysis. Prentice-Hall, Inc., Upper Saddle River, NJ. 
Messier, W. F., Martinov-Bennie, N., Eilifsen, A., 2005. A review and integration of empirical research on materiality: Two decades later. Auditing: A Journal of Practice and Theory 24 (2), 153-188.

Moriarity, S., Barron, F. H., 1979. A judgment-based definition of materiality. Journal of Accounting Research (Supplement), 114-135.

Morris, M. H., Nichols, W. D., 1984. Pension accounting and the balance sheet: The potential effect of the FASB's preliminary views. Journal of Accounting, Auditing and Finance 7,239-305.

-----------------., and -----------------., 1988. Consistency expectations: Materiality judgments and audit firm structure. The Accounting Review 63, 237-254.

Ng, T. B., 2007. Auditors' decisions on audit differences that affect significant earnings thresholds. Auditing: A Journal of Practice \& Theory 26 (1), 7189.

O’Connor, M., Collins, D., 1974. Toward establishing user-oriented materiality standard. Journal of Accountancy (Dec.), 67-75.

Pany, K., Wheeler, S., 1989. Materiality: An inter-ind ustry comparison of the magnitudes and stabilities of various quantitative measures. Accounting Horizons (Dec.), 71-78.

Patillo, J. W., 1975. Materiality: The (formerly) elusive standard. Financial Executive (Aug.), 20-27.

-------------., 1976. The Concept of Materiality in Financial Reporting, Volume 1, Financial Executives Research Foundation.

Pinsker, R., 2007. Long series of information and nonprofessional investors' belief revision. Behavioral Research in Accounting 19, 197-214.

Regulation Fair Disclosure, 2000. SEC Release 33-7881, Rules 101-103.

Ritt, A., 2004. Who is the American shareowner? Better Investing 53 (Jan.), 28-33.

Schipper, K., 2007. Required disclosures in financial reports. The Accounting Review 82 (2), 301-327.

Securities and Exchange Commission, 1999. Materiality. Staff Accounting Bulletin 99. 
Sengupta, P., 2004. Disclosure timing: Determinants of quarterly earnings release dates. Journal of Accounting and Public Policy 23, 457-482.

Shafer, W. E., 2002. Effects of materiality, risk, and ethical perceptions on fraudulent reporting by financial executives. Journal of Business Ethics 38 (3), 243-262.

Shefrin, H.M., Statman, M., 1985. The disposition to sell winners too early and rid losers too long. Journal of Finance 40, 777-790.

Skowronski, J. J., Carlston, D. E., 1989. Negativity and extremity biases in impression formation: A review of explanations. Psychological Bulletin 105, 131-142.

Smith, N. K., Larsen, J. T., Chartrand, T. L., 2006. Being bad isn’t always good: Affective context moderates the attention bias toward negative information. Journal of Personality and Social Psychology 90, 210-220.

Steinbart, P.,1987. Materiality: A case study using expert systems. The Accounting Review (Jan.), 97-116.

Tan, H. T., 1995. Effects of expectations, prior involvement, and review awareness on memory for audit evidence and judgment. Journal of Accounting Research 33 (Spring), 113-135.

----------., Libby, R. R., Hunton, J. E., 2002. Analysts' reactions to earnings pre-announcement strategies. Journal of Accounting Research 40 (March), 223-247.

Taub, S., 2007. Avoiding unnecessary restatements. Compliance Week, May 8, 4 pages.

Tuttle, B., Coller, M., Burton, F G., 1997. An examination of market efficiency: Information order effects in a laboratory market. Accounting, Organizations, and Society 22 (1), 89-103.

-------, -------, Plumlee, R. D., 2002. The effect of misstatements on decisions of financial statement users: An experimental investigation of auditor materiality thresholds.

Auditing: A Journal of Practice and Theory 21, 11-27.

Tversky, A., Kahneman, D., 1974. Judgment under uncertainty: Heuristics and biases. Science 185, 1124-1131.

United States Congress, 2002. Sarbanes-Oxley Act of 2002. Pub. L. 107-204, 116.

Ward, B. H., 1976. An investigation of the materiality construct in auditing. Journal of Accounting Research 14, 138-152. 
Whitehouse, T., 2007. SEC ponders update on materiality standards. Compliance Week, May15, 4 pages.

Wright, A., 1988. The impact of prior working papers on audit evidential planning judgments. Accounting, Organizations and Society (Oct.), 595-606.

Wright, G. B., Taylor, R. D., 1982. Reporting materiality for investors. Journal of Accounting, Auditing and Finance 5, 301-309. 
Table 1

Liquidating Dividends and Probabilities of Occurrence

\begin{tabular}{|c|c|c|c|c|c|c|c|c|c|}
\hline $\begin{array}{c}\text { Dividend } \\
\text { Amount }\end{array}$ & $\begin{array}{c}4 \text { lab } \\
\text { dollars }\end{array}$ & $\begin{array}{c}6 \text { lab } \\
\text { dollars }\end{array}$ & $\begin{array}{c}8 \text { lab } \\
\text { dollars }\end{array}$ & $\begin{array}{c}10 \text { lab } \\
\text { dollars }\end{array}$ & $\begin{array}{c}12 \text { lab } \\
\text { dollars }\end{array}$ & $\begin{array}{c}14 \text { lab } \\
\text { dollars }\end{array}$ & $\begin{array}{c}16 \text { lab } \\
\text { dollars }\end{array}$ & $\begin{array}{c}18 \text { lab } \\
\text { dollars }\end{array}$ & $\begin{array}{c}20 \text { lab } \\
\text { dollars }\end{array}$ \\
\hline Probability & $5 \%$ & $5 \%$ & $10 \%$ & $15 \%$ & $30 \%$ & $15 \%$ & $10 \%$ & $5 \%$ & $5 \%$ \\
\hline
\end{tabular}

${ }^{a}$ Adapted from Tuttle et al. (1997) 
Table 2

\section{Disclosure Cues (Order 1, Non-Practice)}

\section{Title of Item}

Autismo Rated \#1 in Customer Service

Autismo Found to Have Highest Return Over Past

10 Years

Longtime Industry Leader Autismo Faces

Downward

Trend

Autismo Price

Hike Depresses

Demand

Autismo Profits

in its Partnership with Ramble

Manufacturing

Autismo Debuts

Widely

Successful New

Product

Autismo Slows

Down Delivery

Accounting Error

Makes Last

Year's Autismo

Statements

Unreliable

Autismo

"Trades"

Exchanges for

Common Stock
Item Description

As a major reason for our strong financial performance, according to a recent survey, for the fourth year in a row, we have the highest level of customer satisfaction among all companies in our industry.

In a comparison of all wholesale cleanings supplies companies worldwide, by a significant margin, we were found to have the highest return on equity over the past 10 years.

According to most Wall Street experts, it is highly unlikely that we will gain market share in any area of business in the foreseeable future.

The price hike for our newer, low-end products has spurred an extreme decrease in demand for the products, resulting in significantly lower profits.

Our company's unlikely alliance with Ramble Manufacturing has resulted in millions of dollars in additional revenue for us.

Today, we debuted our most anticipated cleaning supplies product ever - one that is expected to gain significant market share from rival Sagee.

A recent independent survey has revealed that we have the slowest wholesaler-to-customer product delivery system of all companies in our industry.

On advice from our external auditor, we must indicate that an error in applying GAAP

(Generally Accepted Accounting Principles) was made last year with respect to various accounts; thus rendering last year's financial statements unreliable.

In an effort to move to a greater source of capital, we have decided to delist our common stock at the current exchange and list it on the bigger, international stock exchange.

\section{Positive Event type or Negative \\ Positive \\ Listed}

Positive Non-listed

Negative Non-listed

Negative Listed

Positive Listed

Positive Listed

Negative Non-listed

Negative Listed

Positive Listed 
Long-term Debt Commitment

Helps Autismo

Autismo’s Board Seen as

Industry's Least Productive

Leaders

Jonathan Jonas'

Daily Growth

Stock Update Autismo

Autismo Beats

Out Sagee for Prestigious

Quality Award

Autismo

Announces

Strong European

Demand for its

Products

Autismo

Defaults on

Loan: Bank

Requests Instant Payment

Autismo's

Environmental

Fine Bad for

Business

Autismo's CEO

Seen as

Industry's Most

Productive

Leader

Lack of

Perceived Ethics

Causes Sagee to

Lose Major

Contract to
Whereas in previous years we typically carried little or no long-term debt, with today's substantial bond offering, our officers claim the company has become tremendously efficient in

its operations.

According to a recent survey of top analysts, our Board of Directors received the lowest rankings for productivity and leadership of any Board in our industry.

"Yesterday, after the close, Autismo web-casted its analyst conference reiterating its incredibly weak, industry-lagging 20 percent revenue decline,” said Jonathan Jonas, an analyst at Jasmine Financial Group.

In a landslide, we beat out competitor Sagee for the prestigious Marks Award for selling quality cleaning products to retailers.

Our second largest market, Europe, has shown a sharp increase in demand for our products, which significantly boosts our bottom line.

Due to inadequate cash flow last month, we defaulted on our biggest bank loan, necessitating us to instantly pay back the remaining millions of dollars still due.

Negative

Listed

Positive Non-listed

Positive

Listed

Negative Listed

Negative Listed illegally dumping toxic chemicals, recent sales to environmentally-friendly consumers are significantly increasing Sagee's revenues at our expense.

According to a recent survey of top analysts, Autismo’s Chief Executive Officer (CEO), Craig

Biggins, received the highest rankings for productivity and leadership of any CEO in the wholesale cleaning supplies industry.

In a startling change in events, Sagee's largest customer has left and gone over to Autismo causing an unanticipated meteoric rise to Autismo’s credibility.

Positive Non-listed

Positive Listed 


\begin{tabular}{|c|c|c|c|}
\hline \multicolumn{4}{|l|}{ Autismo } \\
\hline $\begin{array}{l}\text { Tornado } \\
\text { Severely } \\
\text { Damages }\end{array}$ & $\begin{array}{c}\text { A significant impairment charge had to be levied } \\
\text { against our main warehouse - one of our most } \\
\text { valuable assets }\end{array}$ & Negative & Listed \\
\hline $\begin{array}{l}\text { Autismo’s Main } \\
\text { Warehouse }\end{array}$ & & & \\
\hline $\begin{array}{l}\text { Autismo } \\
\text { Announces } \\
\text { Layoffs of } 1,000 \\
\text { Employees }\end{array}$ & $\begin{array}{l}\text { Due to declining future cash flows, we regret to } \\
\text { announce are laying off } 1,000 \text { employees (or } 35 \% \\
\text { of our workforce) within the next three months. }\end{array}$ & Negative & Non-listed \\
\hline $\begin{array}{l}\text { Autismo's Stock } \\
\text { Offers Poor } \\
\text { Growth }\end{array}$ & $\begin{array}{l}\text { Our stock price has been lower for the past year, } \\
\text { because many analysts believe we offer poor } \\
\text { earnings growth potential. }\end{array}$ & Negative & Listed \\
\hline $\begin{array}{l}\text { B.I.G. } \\
\text { Manufacturing } \\
\text { Chooses Sagee } \\
\text { Over Autismo }\end{array}$ & $\begin{array}{l}\text { Heavy machinery giant B.I.G. decided to } \\
\text { terminate its business alliance with us (Autismo), } \\
\text { in favor of Sagee, which is likely to cause a large } \\
\text { drop in our revenues for the next } 5 \text { years. }\end{array}$ & Negative & Listed \\
\hline $\begin{array}{l}\text { Autismo Raises } \\
\text { Dividends }\end{array}$ & $\begin{array}{c}\text { We are raising quarterly dividends } 50 \% \text { for the } \\
\text { year. }\end{array}$ & Positive & Listed \\
\hline $\begin{array}{l}\text { Autismo Voted } \\
\text { Best Company to } \\
\text { Work For }\end{array}$ & $\begin{array}{l}\text { According to a recent survey of wholesale } \\
\text { cleaning supplies companies' employees, we } \\
\text { were voted the best place to work, while rival } \\
\text { Sagee was not even in the top } 100 \text { companies. }\end{array}$ & Positive & Non-listed \\
\hline
\end{tabular}


Table 3

Mean Weights (Standard Deviations) Generated by Participants for Disclosures

\begin{tabular}{|c|c|c|c|c|}
\hline $\begin{array}{c}\text { Disclosure } \\
\#\end{array}$ & $\begin{array}{l}\text { Intended } \\
\text { Direction }\end{array}$ & Mean & $\begin{array}{l}\text { Standard } \\
\text { Deviation }\end{array}$ & $\begin{array}{c}\text { Disclosure } \\
\text { Type }\end{array}$ \\
\hline 1 & + & 5.02 & 2.56 & Listed \\
\hline 2 & + & 7.31 & 2.25 & Non-listed \\
\hline 3 & - & -5.96 & 2.44 & Non-listed \\
\hline 4 & - & -6.65 & 2.04 & Listed \\
\hline 5 & + & 6.48 & 1.94 & Listed \\
\hline 6 & + & 5.73 & 2.39 & Listed \\
\hline 7 & - & -3.77 & 2.55 & Non-listed \\
\hline 8 & - & -5.88 & 3.15 & Listed \\
\hline 9 & + & 3.08 & 2.40 & Listed \\
\hline 10 & + & 4.23 & 2.70 & Listed \\
\hline 11 & - & -5.13 & 2.41 & Non-listed \\
\hline 12 & - & -5.25 & 2.66 & Listed \\
\hline 13 & + & 4.46 & 2.08 & Non-listed \\
\hline 14 & + & 5.77 & 2.33 & Listed \\
\hline 15 & - & -6.85 & 2.48 & Listed \\
\hline 16 & - & -6.42 & 2.07 & Listed \\
\hline 17 & + & 4.62 & 2.33 & Non-listed \\
\hline 18 & + & 6.50 & 2.22 & Listed \\
\hline 19 & - & -5.65 & 2.20 & Listed \\
\hline 20 & - & -5.63 & 2.86 & Non-listed \\
\hline 21 & - & -5.00 & 2.33 & Listed \\
\hline 22 & - & -7.17 & 2.22 & Listed \\
\hline 23 & + & 6.06 & 2.45 & Listed \\
\hline 24 & + & 4.17 & 2.79 & Non-listed \\
\hline
\end{tabular}

a The disclosures are listed according to order 1 (see table 2), although the data includes all three experimental market sessions. 
Table 4

Mean Market Price Generated by Participants

Order 1

(In Order Viewed by Participants) $^{\mathrm{a}}$

\begin{tabular}{|c|c|c|c|c|c|}
\hline $\begin{array}{l}\text { Disclosure } \\
\#\end{array}$ & $\begin{array}{l}\text { Mean Price } \\
\text { (S.D.) }\end{array}$ & $\begin{array}{l}\text { Mean } \\
\text { Difference }\end{array}$ & $\begin{array}{r}\text { Dis } \\
\# \\
\end{array}$ & $\begin{array}{l}\text { Ire Mean Price } \\
\text { (S.D.) }\end{array}$ & $\begin{array}{l}\text { Mean } \\
\text { Difference }\end{array}$ \\
\hline 1 & $\$ 11.24(2.89)$ & $\$ 0.76^{* * * d}$ & 23 & $\$ 12.38(1.78)$ & $\$ 0.38$ \\
\hline 2 & $11.78(1.61)$ & $0.57 *^{\mathrm{cd}}$ & 24 & 11.70 (1.11) & $0.56 *$ \\
\hline 3 & 10.39 (1.15) & $1.38 * * * \mathrm{~cd}$ & 21 & $8.68(2.58)$ & $3.30 * * * \mathrm{~cd}$ \\
\hline 4 & 9.59 (1.88) & $0.78 * * * \mathrm{~cd}$ & 22 & 7.52 (2.15) & $1.51 * * * \mathrm{~cd}$ \\
\hline 5 & 11.19 (1.13) & $1.56 * * * \mathrm{~cd}$ & 3 & $10.19(1.78)$ & $1.81 * * * \mathrm{~d}$ \\
\hline 6 & $11.11(0.61)$ & $0.08^{\mathrm{C}}$ & 4 & 9.65 (1.14) & $0.31^{\mathrm{c}}$ \\
\hline 7 & $11.17(1.11)$ & 0.09 & 1 & 10.54 (0.95) & $0.88 * * *$ cd \\
\hline 8 & $10.51(1.27)$ & $0.73 * * * \mathrm{~cd}$ & 2 & $11.08(0.49)$ & $0.61 * * * \mathrm{~cd}$ \\
\hline 9 & $10.96(0.50)$ & $0.56 * * * \mathrm{~cd}$ & 7 & $10.59(0.72)$ & $0.49 * * * \mathrm{~cd}$ \\
\hline 10 & $10.93(0.23)$ & $0.06^{\mathrm{C}}$ & 8 & $10.57(1.04)$ & $0.08^{\mathrm{C}}$ \\
\hline 11 & $10.97(0.23)$ & $0.04^{\mathrm{C}}$ & 5 & $12.31(0.63)$ & $1.726 * * *$ cd \\
\hline 12 & $10.89(0.07)$ & $0.07 * \mathrm{~d}$ & 6 & $12.28(0.70)$ & $0.05^{\mathrm{C}}$ \\
\hline 13 & $10.98(0.40)$ & $0.10^{\mathrm{d}}$ & 11 & 11.11 (0.69) & $1.17 * * * \mathrm{~cd}$ \\
\hline 14 & $11.01(0.13)$ & $0.01^{\mathrm{c}}$ & 12 & $11.44(0.85)$ & 0.09 \\
\hline 15 & $10.84(0.43)$ & $0.18 * * \mathrm{~cd}$ & 9 & $11.68(0.49)$ & $0.39 * * *$ \\
\hline 16 & $10.76(0.21)$ & $0.09^{c}$ & 10 & $11.77(0.40)$ & $0.03^{c}$ \\
\hline 17 & $10.91(0.04)$ & $0.17 * * * \mathrm{~cd}$ & 15 & $11.34(0.68)$ & $0.41 * * *$ cd \\
\hline 18 & $10.92(0.05)$ & $0.08^{\mathrm{C}}$ & 16 & $11.60(0.75)$ & $0.24 *^{\mathrm{C}}$ \\
\hline 19 & $10.88(0.08)$ & $0.04 * * \mathrm{~cd}$ & 13 & $11.65(0.53)$ & $0.19^{c}$ \\
\hline 20 & $10.67(0.07)$ & $0.21 * * * \mathrm{~cd}$ & 14 & $11.79(0.63)$ & $0.06^{\mathrm{C}}$ \\
\hline 21 & $10.80(0.09)$ & $1.20 * * * \mathrm{~d}$ & 19 & $11.48(0.66)$ & $0.35 * *$ cd \\
\hline 22 & $10.70(0.13)$ & $0.09 * * * \mathrm{~cd}$ & 20 & $11.44(0.46)$ & $0.07^{\mathrm{c}}$ \\
\hline 23 & $10.85(0.19)$ & $0.14 * * * \mathrm{~cd}$ & 17 & $11.60(0.54)$ & $0.14^{\mathrm{C}}$ \\
\hline 24 & $10.84(0.06)$ & $0.01^{\mathrm{C}}$ & 18 & 12.09 (0.38) & $0.49 * * *$ cd \\
\hline
\end{tabular}

\footnotetext{
* $\quad$ Significant at $p=0.10$

** $\quad$ Significant at $p=0.05$

$* * * \quad$ Significant at $p=0.01$

a The disclosure numbers below are defined according to order 1 (see table 2)

b This number is calculated as the absolute value mean difference between the

disclosure and either $\$ 12$ (for $t$-tests) or the disclosure immediately preceding it. For the ANOVAs, this number is taken from the marginal, rather than the raw means presented in the table, in order to take into account the within-subject trader id variables.

c ANOVA results agree with the Kruskal-Wallis results.

d This disclosure is considered material using an alpha of 0.05 .
} 
Table 5

Summary of Findings

Research

Quest./Hypothesis

Research Question 1

Hypothesis 1

Hypothesis 2

$\begin{array}{cccc}\text { Subject Matter } & \chi^{2} & p \text {-value }^{\mathrm{a}} & \text { Supported? } \\ \begin{array}{c}\text { Listed vs. Non- } \\ \text { listed }\end{array} & 1.22 & 0.54 & \text { N/A } \\ \begin{array}{c}\text { Negative vs. } \\ \text { Positive }\end{array} & 2.13 & 0.14 & \text { No } \\ \text { Anchoring } & 4.07 & 0.04 & \text { Yes }\end{array}$

a The Chi-square and $p$-values are from the logistic regression analyses only. 
Figure 1

Mean Stock Prices for Each Disclosure and Order

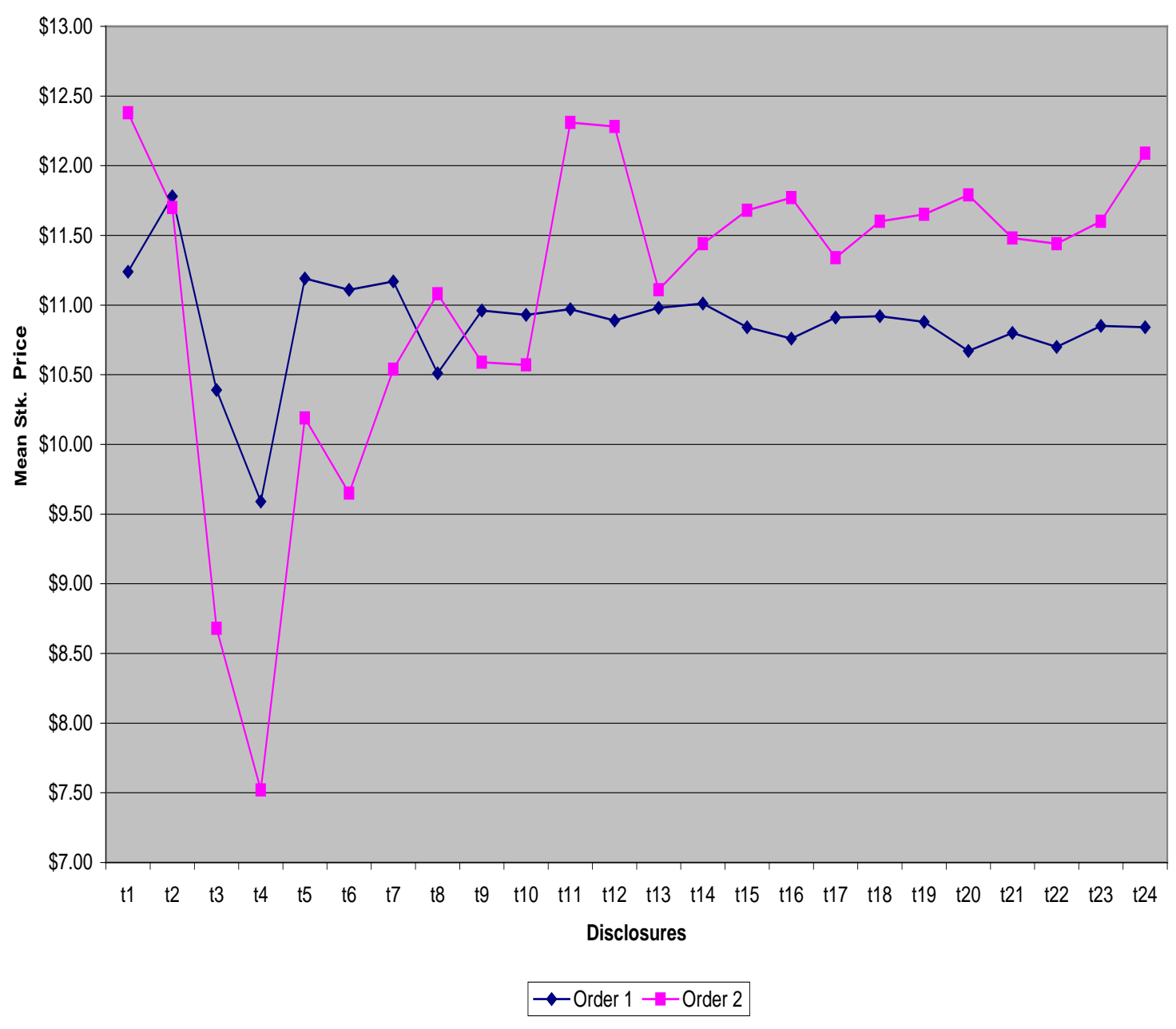

